\title{
Overexpression of SERPIN B3 promotes epithelial proliferation and lung fibrosis in mice
}

\author{
Francesca Lunardi ${ }^{1, *}$, Gianmarco Villano ${ }^{2, \star}$, Egle Perissinotto ${ }^{3}$, Carlo Agostini ${ }^{2}$, Federico Rea ${ }^{4}$, Marianna Gnoato ${ }^{2}$, \\ Alice Bradaschia ${ }^{5}$, Marialuisa Valente ${ }^{1}$, Patrizia Pontisso ${ }^{2}$ and Fiorella Calabrese ${ }^{1}$
}

SERPIN B3/B4, members of the serpin superfamily, are fundamental for the control of proteolysis through a known inhibitory function of different proteases. Several studies have documented an important role of SERPIN B3 in the modulation of inflammation, programmed cell death and fibrosis. To confirm the role of SERPIN B3 in lung fibrosis and overall investigate its influence on epithelial dysfunction, a stratified controlled trial randomly assigning bleomycin (BLM) treatment was performed on both SERPIN B3 transgenic (TG) and wild-type (WT) mice. TG and WT animals were killed $48 \mathrm{~h}$ (group T48 h) and 20 days (group T20d) after BLM treatment. Lung fibrosis was assessed by histology and hydroxyproline measurement. Architectural remodeling, inflammation, epithelial apoptosis and proliferation were quantified. Moreover, the profibrogenetic cytokine transforming growth factor (TGF)- $\beta$, cathepsin $\mathrm{K}, \mathrm{L}$ and $\mathrm{S}$ were also investigated. No significant differences were observed between TG and WT mice of group T48 h in any parameters. In group T20d, less inflammation and a significant increase in epithelial proliferation were detected in treated TG than WT mice despite a similar apoptotic index, thus resulting in a different apoptosis/proliferation imbalance with a significant gain of epithelial proliferation. Moreover, TG mice showed higher TGF- $\beta$ expression and more extended fibrosis. General linear model analysis, applied on morphological data, showed that interaction between SERPIN B3 expression and treatment was mainly significant for fibrosis. This study provides in vivo evidence for a role of SERPIN B3 in inhibiting inflammation and favoring epithelial proliferation with increased TGF- $\beta$ secretion and thus the likelihood of consequent fibrogenesis. Laboratory Investigation (2011) 91, 945-954; doi:10.1038/labinvest.2011.1; published online 14 March 2011

KEYWORDS: animal model; bleomycin; lung fibrosis; proliferation; SERPIN B3

Idiopathic pulmonary fibrosis (IPF), with its histopathological signature of usual interstitial pneumonia, is a devastating form of interstitial lung disease of unknown etiology. The pathogenesis of pulmonary fibrosis is poorly understood and has been the subject of many investigations. Historically, inflammation has been viewed as central to the pathogenesis of IPF. ${ }^{1}$ A recent paradigm shift proposes a model in which injury to the epithelium initiates a proinflammatory and profibrotic cascade, resulting in fibroblast expansion and progressive fibrosis reminiscent of abnormal wound healing. ${ }^{2}$ An increased body of evidence now recognizes epithelial apoptosis as an important early feature in IPF $^{3}$ and in murine models of bleomycin (BLM)-induced lung fibrosis. ${ }^{4}$
After injury epithelial repair has a pivotal role in normal wound-healing processes. ${ }^{5}$ Abnormal re-epithelization with aberrant proliferation of metaplastic cells (bronchial, squamous and cuboidal) is another important aspect frequently observed in highly remodeled fibrotic areas of IPF lungs as honeycomb lesions.

A higher proliferation index and epithelial dysplasia have frequently been detected in honeycomb: these areas represent a site of high instability at risk of neoplastic transformation. ${ }^{6}$ An increased incidence of carcinomas, such as squamous cell carcinoma and adenocarcinoma, mainly located in peripheral lung areas, has been reported in IPF patients. ${ }^{7-9}$ Whether the appearance of abnormal epithelial cells protects or promotes fibrosis remains uncertain. $^{10}$ Several experimental and

\footnotetext{
${ }^{1}$ Department of Diagnostic Medical Sciences and Special Therapies, University of Padua, Padua, Italy; ${ }^{2}$ Department of Clinical and Experimental Medicine, University of Padua, Padua, Italy; ${ }^{3}$ Department of Environmental Medicine and Public Health, University of Padua, Padua, Italy; ${ }^{4}$ Department of Cardiac, Thoracic and Vascular Sciences, University of Padua, Padua, Italy and ${ }^{5}$ Department of Biomedical Sciences, University of Padua, Padua, Italy

Correspondence: Professor F Calabrese, MD, Department of Diagnostic Medical Sciences and Special Therapies, University of Padua, Via Gabelli 61, Padua 35121, Italy. E-mail: fiorella.calabrese@unipd.it

*These authors contributed equally to this work.

Received 25 February 2010; revised 3 December 2010; accepted 3 December 2010
} 
human studies reported a pro-fibrogenetic influence of metaplastic epithelial cells through the secretion of factors favoring fibrotic processes. ${ }^{11,12}$ More extensive lung fibrosis has recently been reported in IPF lungs with metaplastic epithelial cells that showed an overproduction of squamous cell carcinoma antigen (SCCA) and transforming growth factor (TGF) $-\beta .^{13}$ In that study, the influence of SCCA on favoring epithelial TGF- $\beta$ secretion was also corroborated by an in vitro model. ${ }^{13}$

SCCA 1 and 2, renamed according to the new nomenclature guidelines as SERPIN B3 and B4, ${ }^{14}$ inhibit several types of proteases. A large amount of biochemical and biophysical information reveals that serpins are 'suicide' or 'single use' inhibitors that use a unique and extensive conformational change to inhibit proteases. ${ }^{15}$

SERPIN B3 (SCCA 1) displays inhibitory activities on serine proteinase, for example, chymotrypsin, and cysteine proteinase, such as cathepsin $\mathrm{L}, \mathrm{K}, \mathrm{S}$ and papain, whereas SERPIN B4 (SCCA 2) inhibits serine proteinases, such as cathepsin G, human mast cell chymase and cysteine proteinases (eg, Der p1 and Der f1). ${ }^{16}$ Several in vitro and in vivo studies have documented an important role of SERPIN B3 in the modulation of programmed cell death by different mechanisms, both in inflammatory and neoplastic processes. ${ }^{17}$ To understand the role of SERPIN B3 in lung epithelial proliferation and its influence on architectural remodeling (AR) (inflammation and fibrosis), a stratified controlled trial was randomly performed assigning BLM treatment to both SERPIN B3 transgenic and wild-type mice (TG and WT, respectively).

BLM-induced pneumopathy in mice is a well-known animal model of lung injury and fibrosis. Significant epithelial loss through apoptotic cell death has been reported as an early event after BLM treatment. ${ }^{18}$

To further detect the early and late influence of SERPIN B3 in BLM lung injury, the animals were killed at $48 \mathrm{~h}$ and 20 days after treatment.

\section{SUBJECTS AND METHODS Animal Models}

The study was carried out on $30 \mathrm{C} 57 \mathrm{BL} / 6$ mice transgenic for human SERPIN B3. Human SERPIN B3 cDNA $(-7 /+1238)^{19}$ was placed in the region downstream from the $\alpha 1$-antitripsin promoter and upstream from the bGH polyadenylation region. The whole construct was inserted in the plasmid pcDNA3 and injected into the pronucleus of fertilized eggs obtained from C57BL/6 mice.

The mice used for the experiments were 12-14 weeks old. Thirty age-matched C57BL/6 mice were used as controls.

Mice were all kept under specific pathogen-free conditions and maintained with free access to pellet food and water at the Animal Care Facility of the Experimental Surgery Division, University of Padua, Italy. Experiments were done in accordance with the Helsinki convention and institute guidelines and regulations.

\section{TG Mice Characterization}

\section{Evaluation of human SERPIN B3 homozygosis and tissue expression}

(1) The homozygous form of SERPIN B3 was assessed in TG mice by qualitative and quantitative polymerase chain reaction (PCR), analyzing genomic DNA isolated from mice tails using a phenol/chloroform method. Total DNA was extracted from frozen tissue using $1 \mathrm{ml}$ of TRIzol reagent (Invitrogen, Carlsbad, CA, USA) following the manufacturer's instructions, briefly dried up and dissolved in DNase-free water. Briefly, $40 \mathrm{ng}$ of DNA was analyzed using primers specific for human SERPIN B3 (sense: $5^{\prime}$-GCAAATGCTCCAGAAGAAAG- $3^{\prime}$ and antisense: $5^{\prime}$-CGAGGCAAAATGAAAAGATG- $3^{\prime}$ ) and for the mouse housekeeping gene actin (sense: $5^{\prime}$-AGCCATGT ACGTAGCCATCC- $3^{\prime}$ and antisense: $5^{\prime}$-CTCTCAGCT GTGGTGGTGAA-3'), designed using Primer express software. SYBR green real-time PCR was performed in a Light Cycler Apparatus (Roche, Monza, Italy), using a FastStart DNA Master PLUS SYBR Green Kit (Roche). After an initial denaturation step at $95^{\circ} \mathrm{C}$ for $10 \mathrm{~min}, 45$ cycles of amplification were carried out and included the following conditions: denaturation at $94^{\circ} \mathrm{C}$ for $1 \mathrm{~s}$, annealing at $62^{\circ} \mathrm{C}$ for $10 \mathrm{~s}$ and extension at $72{ }^{\circ} \mathrm{C}$ for $10 \mathrm{~s}$. A final extension step was performed at $37^{\circ} \mathrm{C}$ for $1 \mathrm{~min}$. In every amplification, a homozygous sample as a positive control and a WT sample as a negative control were introduced. Amplification of specific transcripts was confirmed by melting curve profiles at the end of each PCR cycle using the specific routine built-up in the Light Cycler instrument.

(2) To better characterize the TG mouse model, the expression of human SERPIN B3 was assessed in TG mice by real-time reverse transcriptase-PCR. Total RNA was extracted from different organ frozen tissues using $1 \mathrm{ml}$ of TRIzol reagent (Invitrogen) following the manufacturer's instructions, briefly dried up and dissolved in RNase-free water. Two micrograms of extracted RNA for each tissue sample were reverse transcribed into cDNA first-strand by First-Strand cDNA Synthesis kit (Invitrogen) using $200 \mathrm{U}$ of SuperScript II Reverse Transcriptase and $0.5 \mu \mathrm{g}$ of oligo dT (Invitrogen). SYBR Green real-time PCR for human SERPIN B3 was performed in the liver, brain, lung, genitals, kidney and muscle as described above and the relative quantification of human SERPIN B3 was achieved comparing the expression of this gene with the housekeeping gene $\beta$-actin according to $\Delta \Delta \mathrm{CT}$ formula.

(3) The expression of mouse SERPIN B3 was assessed in TG and WT mice by real-time PCR (primer sense $5^{\prime}$-TC CTAGTGGGAGCCTAAGCA- $3^{\prime}$ and antisense $5^{\prime}$-ATCCC CCAGAAAGCTGAAGT- $3^{\prime}$ ) as described above and compared with the expression of homologous human SERPIN B3. The relative quantification of mouse SERPIN B3 genes was achieved in frozen lung biopsies by the 
expression of the housekeeping gene ( $\beta$-actin) according to $\Delta \Delta \mathrm{CT}$ formula. All data are expressed as mean \pm s.d.

(4) Human SERPIN B3 protein expression was investigated in all samples by immunohistochemistry. Four $\mu \mathrm{m}$-thick sections were cut and processed. Briefly, after dewaxing and hydration, sections were incubated in citrate buffer $5 \mathrm{mM}$ at $\mathrm{pH} 6.0$ in a microwave oven for $30 \mathrm{~min}$ for antigen retrieval. Afterward, sections were treated with normal serum (BioOptica, Milan, Italy) and incubated for $60 \mathrm{~min}$ with the primary polyclonal antibody anti-human SERPIN B (Xeptagen, Marghera, Italy) at a concentration of 1:5 overnight. Sections were subsequently incubated with EnVision System HRP polymer anti-rabbit (Dako, Glostrup, Denmark) for $30 \mathrm{~min}$. Immunoreactivity was visualized with 3-3'-diaminobenzidine (Dako). Sections were counterstained with hematoxylin for $1 \mathrm{~min}$. Negative controls for nonspecific binding were processed omitting the primary antibodies, and revealed no signal.

\section{BLM-Induced Lung Damage}

Intratracheal instillation of BLM was performed in 40 mice (20 TG and $20 \mathrm{WT}$ ). Briefly, BLM was dissolved at a concentration of $1.25 \mathrm{U} / \mathrm{ml}$ of sterile phosphate-buffered saline (PBS) and vortexed extensively before each $100-\mu$ l aliquot $(2.5 \mathrm{U} / \mathrm{kg})$ was used. The mice were anesthetized and intratracheal instillation was then performed slowly. Twenty animals were treated with PBS as the control group.

We killed 20 mice (10 TG and $10 \mathrm{WT}$ ) at $48 \mathrm{~h}$ after BLMtreatment to investigate the early changes because of BLMmediated injury. Both in vivo and in vitro studies have demonstrated that the highest apoptotic index (AI) was detected between 1 and 3 days after the treatment ${ }^{20,21}$ and our 48-h time point has been chosen because it was exactly in the middle of the interval (group T48 h). To detect the late influence of SERPIN B3, 40 animals were killed 20 days after BLM or PBS treatment (group T20d) because the majority of experimental models showed at that time the most extended fibrotic remodeling. ${ }^{22}$ At both times mice were weighed, anesthetized, heparinized and exsanguinated via the femoral artery. The heart and lungs were then removed en bloc. Lungs were inflated by intratracheal perfusion with PBS-buffered formaldehyde solution at a constant pressure of $20 \mathrm{mmH}_{2} \mathrm{O}$ and then preserved in the solution for at least $24 \mathrm{~h}$ at room temperature. The lungs, sectioned parasagittally superior to inferior, were embedded in paraffin. Sections of $5 \mu \mathrm{m}$ were prepared and stained with hematoxylin/eosin (H\&E) and Azan-Mallory for morphological studies as previously described. ${ }^{23}$

\section{Morphological Analysis}

AR consisted of altered lung areas occupied by inflammation, fibrosis and vessel remodeling. Remodeled lung areas were selected by morphometrical software (Image Pro-plus V.5) in H\&E stained sections and appeared as more condensed 'purple regions' (hematoxyphylic stained areas). In the histo- logical panoramic view $(1 \times$-fold $)$ magnification, the AR was calculated dividing the total AR extension by the total tissue area of the section (where $n=$ the number of fields): $\mathrm{AR}=\Sigma$ nAR extension/total Area $\times 100$.

The extent of fibrosis and inflammation was evaluated respectively in Azan-Mallory and in H\&E stained sections analyzing 10 random fields in the same section of imaged lesions at 50-fold magnification, excluding the areas of honeycombing and patrimonial peribronchiolar and septal fibrosis. In each selected field, the ratio of fibrotic and inflamed areas was calculated, dividing the total fibrotic and inflamed areas by the total tissue area of the section (where $n=$ the number of fields):

- Fibrosis ratio $=\Sigma \mathrm{n}$ fibrotic area/total area $\times 100$.

- Inflammation ratio $=\Sigma \mathrm{n}$ inflamed area/total area $\times 100$

For each animal, the ratios obtained from the analyzed sections were then averaged. All parameters exclusively related to lung tissue (excluding air spaces) were measured to normalize the effect of collapse or expansion of lung tissue during sampling or tissue fixation. ${ }^{13}$

\section{Determination of Hydroxyproline}

The hydroxyproline (OH-Pro) content of mouse lung was determined by standard methods as previously described. ${ }^{24}$ Briefly, after rinsing with PBS, the lung was defatted, dried, weighed and hydrolyzed for $22 \mathrm{~h}$ at $110^{\circ} \mathrm{C}$ in $6 \mathrm{~N} \mathrm{HCl}$. Aliquots were then assayed by adding chloramine $\mathrm{T}$ solution for $20 \mathrm{~min}, 3.15 \mathrm{M}$ perchloric acid for $5 \mathrm{~min}$, and Erlich's reagent at $60^{\circ} \mathrm{C}$ for $20 \mathrm{~min}$. Absorbance was measured at $561 \mathrm{~nm}$, and the amount of OH-Pro was determined against a standard curve. Results were expressed as percentage of collagen content (weight/weight) relative to dry weight of the tissue sample, considering that OH-Pro accounts for approximatively $11.8 \%$ of the amino acid content. ${ }^{24}$

\section{Quantitative Real-Time PCR for TGF- $\beta$, Cathepsins K, $S$ and $L$}

The expression of mouse TGF- $\beta$, cathepsins $\mathrm{K}, \mathrm{S}$ and $\mathrm{L}$ was assessed in TG and WT mice by real-time PCR (TGF- $\beta$ : primer sense $5^{\prime}$-TTGCTTCAGCTCCACAGAGA- $3^{\prime}$ and antisense $5^{\prime}$ TGGTTGTAGAGGGCAAGGAC- $3^{\prime}$; cathepsin K: primer sense $5^{\prime}$-GCAAATCTCTGCCCATAACC- $3^{\prime}$ and antisense $5^{\prime}$-CCCGT CATCTTCTGAACCAC-3'; cathepsin S: primer sense $5^{\prime}$-GGT TGGCTATGGGACTCTTG- $3^{\prime}$ and antisense $5^{\prime}$-GCAATTCC GCAGTGATTTTT- $3^{\prime}$; cathepsin L: primer sense 5'-GTGGAC TGTTCTCACGCTCA- $3^{\prime}$ and antisense $5^{\prime}$-TGTCATTAGCCA CAGCGAAC- $3^{\prime}$ ) as described above. The relative quantification of mouse TGF- $\beta$, cathepsins $\mathrm{K}, \mathrm{S}$ and $\mathrm{L}$ were achieved in frozen lung biopsies comparing the expression of the gene with the housekeeping gene $\beta$-actin according to $\Delta \Delta \mathrm{CT}$ formula.

\section{Bronchiolar Metaplasia Grading}

Alveolar metaplasia was identified as cells resembling bronchiolar epithelium lining normal or thickened alveolar 
walls. In all sections, an experienced pathologist (FC) graded each bronchiolization from I to IV using an appropriate grading system. ${ }^{11}$ The presence of dysplasia of the metaplastic cells and neoplastic transformation were evaluated on the sections stained with H\&E.

\section{Immunohistochemistry for Proliferation Analysis}

Four- $\mu \mathrm{m}$ thick sections were cut and processed for immunohistochemical analysis of Ki-67 to detect proliferating cells. Briefly, after dewaxing and hydration, sections were incubated in citrate buffer $5 \mathrm{mM}$ at $\mathrm{pH} 6.0$ in a microwave oven for $30 \mathrm{~min}$ for antigen retrieval. Afterward, sections were treated with normal serum (Immunotech, Marseille, France) and incubated for $60 \mathrm{~min}$ with the primary monoclonal antibody anti-Ki67 (MIB-1, Genetex, Irvine, CA, USA) at a concentration of 1:100. Sections were subsequently incubated with rabbit HRP polymer (Dako) for $30 \mathrm{~min}$. Immunoreactivity was visualized with 3-3'-diaminobenzidine (Dako). Negative controls for nonspecific binding were processed omitting the primary antibody and revealed no signal. Ki-67 immunostaining was randomly evaluated counting at least 100 nuclei. The percentage of positive nuclei was expressed as the proliferative index (PI).

\section{Terminal Deoxynucleotidyltransferase-Mediated dUTP-Biotin Nick End-Labeling Method for Apoptotic Evaluation}

Terminal deoxynucleotidyltransferase-mediated dUTP-biotin nick end-labeling method was used to investigate the presence of apoptosis. Sections were processed in accordance with Gavrieli's method. ${ }^{25}$ Briefly, after deparaffinization and rehydration, sections were digested with proteinase $\mathrm{K}$ (Boehringer, Mannheim, Germany) at a concentration of $20 \mu \mathrm{g} / \mathrm{ml}$ for $15 \mathrm{~min}$. The slides were then incubated with TdT/biotinylated dUTP diluted in buffer (Boehringer) and developed by using 3-3'-diaminobenzidine and $30 \mathrm{ml}$ hydrogen peroxide. For negative controls, some slides were incubated in buffer without TdT or biotinylated UTP. For positive controls, some slides were incubated with $1 \mu \mathrm{g} / \mathrm{ml}$ DNAse (Sigma-Aldrich, Milan, Italy). The terminal deoxynucleotidyltransferase-mediated dUTP-biotin nick endlabeling method positivity was randomly evaluated counting at least 100 nuclei. The percentage of positive nuclei was expressed as the AI.

\section{Statistical Analysis}

As the study investigated the role of SERPIN B3 in lung epithelial dysfunction, the results were obtained by comparing the morphologic alterations between WT and TG mice, by time of killing and treatment group. The quantitative variables evaluating the morphologic alterations are described by mean values and s.d., while for binary responses the proportion of events is expressed as percentage. The significance of the difference between mean values was obtained using the Mann-Whitney test, while the comparison between proportions was applied by means of Fisher's test. Taking into account the design effect of the study, a two-way analysis of variance was performed by applying the SAS PROC GLM (general linear models), general linear models were applied to evaluate the independent role of the covariates of SERPIN B3, treatment and their interaction on the morphological alterations.

The significance level was fixed at 0.05 , and all tests were two-tailed. All the analyses were performed using the SAS statistical software rel. 9.1 (SAS Institute, Cary, NC, USA).

\section{RESULTS}

\section{TG Mice Characterization}

\section{Evaluation of human SERPIN B3 homozygosis and tissue} expression

Homozygosis for the human SERPIN B3 gene was assessed by qualitative and quantitative PCR approaches: homozygous TG mice presented detectable threshold cycles $(\Delta \mathrm{Ct}: 1$. $03 \pm 0.01)$ and WT mice did not show amplification for the target gene. The analyses were performed in homozygous TG mice (Figure 1a).

Human SERPIN B3 mRNAs were detectable by real-time RT-PCR in all the examined organs of all TG mice. The amount of transcripts was higher in the brain $(22.2 \pm 11.0 \mathrm{pg} /$ $\mu \mathrm{g} \quad$ RNA $)$, lung $(17.5 \pm 0.7 \mathrm{pg} / \mu \mathrm{g} \quad \mathrm{RNA})$ and liver $(11.2 \pm 2.5 \mathrm{pg} / \mu \mathrm{g} \mathrm{RNA})$, while it was trivial in the genitals $(6.0 \pm 1.1 \mathrm{pg} / \mu \mathrm{g}$ RNA for testicle and $4.5 \pm 1.1 \mathrm{pg} / \mu \mathrm{g}$ RNA for ovary), kidney and muscle ( $<0.6 \mathrm{pg} / \mu \mathrm{g}$ RNA) (Figure $1 \mathrm{~b})$.

None of TG and WT mice lung tissues showed detectable levels of the mouse SERPIN B3 in the same experimental conditions. Specificity of all PCR products was confirmed by agarose gel electrophoresis (Figure 1c).

TG mice showed a strong immunostaining for human SERPIN B3, mainly detected in the cytoplasm of inflammatory cells (mainly macrophages). In the GroupT20d, SERPIN B3 was more evident as it was also expressed in metaplastic alveolar epithelial cells (Figures 2a and b).

\section{Morphological Analysis Group T48h}

All the evaluated morphological parameters were hardly detected in control mice treated with PBS, with no statistical differences between the two groups (WT and TG).

No significant differences were found between WT and TG mice treated with BLM, also including AI.

\section{Group T20d}

The results of the morphological alterations in the mice after 20 days are shown in Table 1 by type (WT, TG) and treatment (PBS, BLM) group.

Considering PBS-treated mice, fibrosis and neoplastic transformations were never found in either WT or TG mice. Bronchiolization, AR and inflammation mean values were not significantly different between WT and TG, similarly to the AI. TG mice showed a higher mean value of PI than WT, 
a
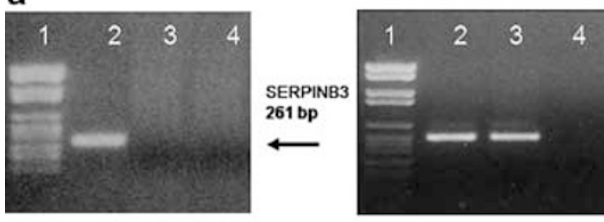

b

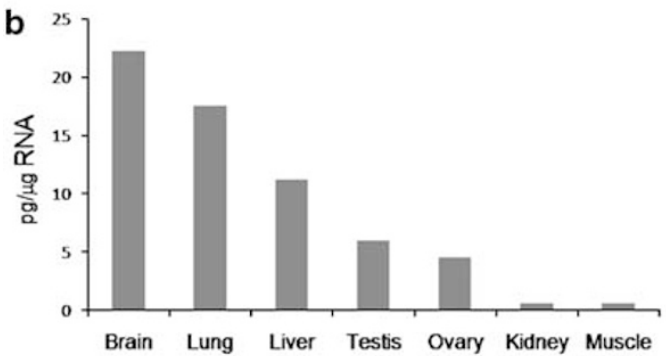

C
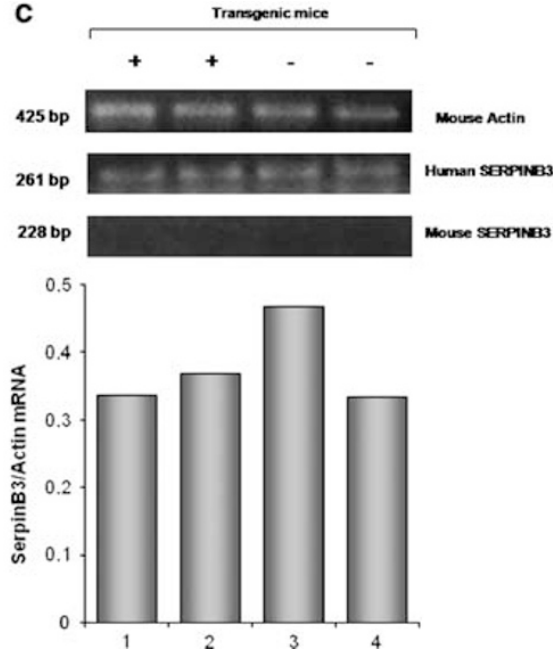

Figure 1 (a-c) Homozygosis for human SERPIN B3 assessment by qualitative and quantitative PCR (a). Agarose gel electrophoresis for PCR of the housekeeping gene actin and SERPIN B3 DNA in emblematic cases. Actin is detected as a 425-base pair (bp) and SERPIN B3 as a 261-bp PCR product. Lane 1: DNA molecular weight marker; lane 2: SERPIN B3 TG animals; lane 3: WT mice; lane 4: negative control. Human SERPIN B3 mRNA expression in different organs of TG mice (b). The amount of transcripts was higher in the brain, lung and liver. Human and mouse SERPIN B3 mRNA expression in TG animals (c). Agarose gel electrophoresis for PCR of the mouse housekeeping gene actin, human and mouse SERPIN B3 in emblematic TG cases, both treated with BLM $(+)$ and PBS (-). Actin is detected as 425-(bp), human SERPIN B3 as 261-bp and mouse SERPIN B3 as 228-bp PCR products. Human SERPIN B3 expression normalized to $\beta$-actin is displayed in the histogram.

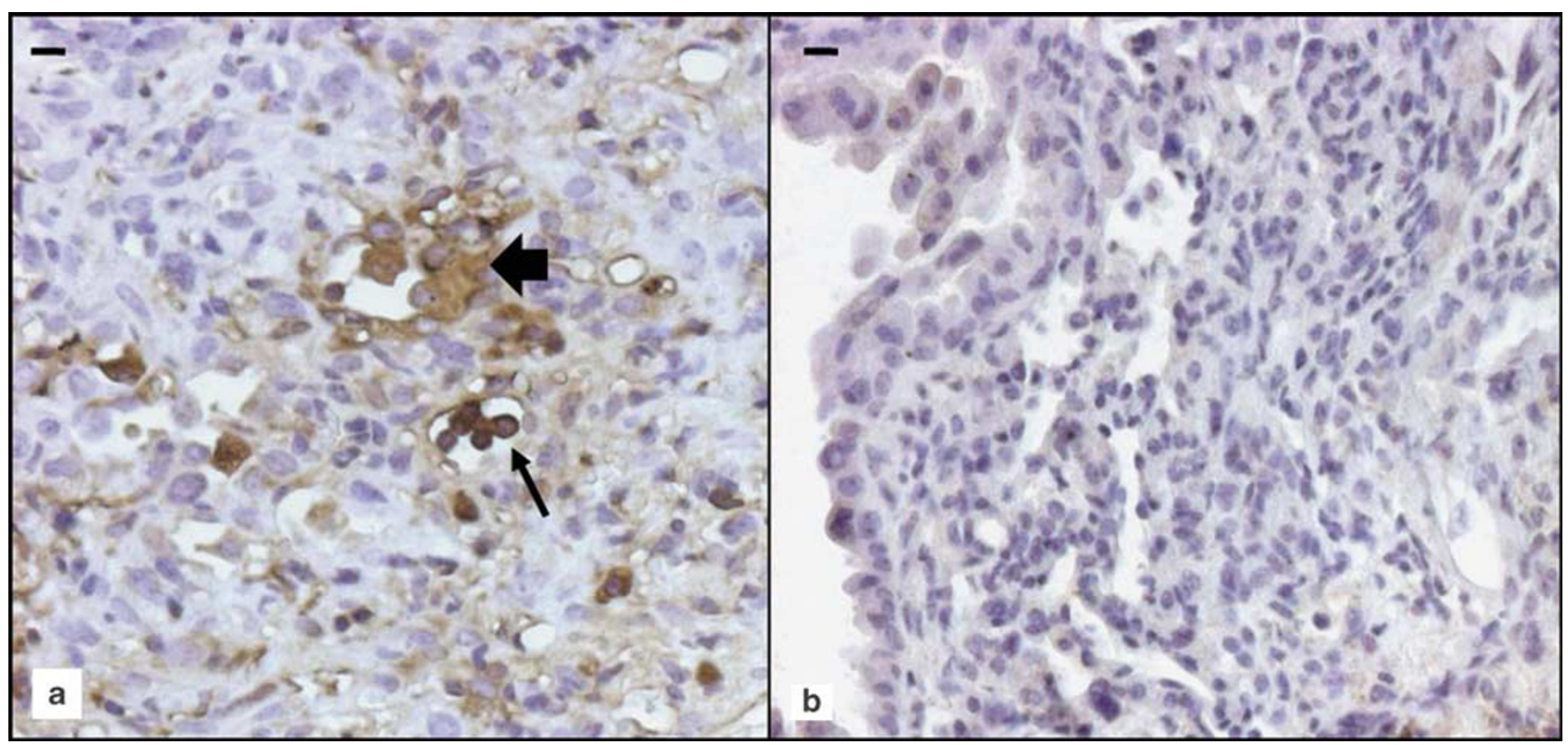

Figure 2 (a, b) Group T20d, immunohistochemistry for human SERPIN B3. Bar $=1 \mu \mathrm{m}$. TG/BLM mice showed strong cytoplasmic immunostaining both in metaplastic epithelial (arrow) and in inflammatory (thin arrow) cells (a). WT animals did not show any specific immunostaining (b).

although they did not reach the statistical significance $(P=0.07)$.

In the BLM-treated group, AR mean value was not significantly different between WT and TG mice $(23.1 \pm 15.3 \%$ vs $16.8 \pm 9.7 \%$ ) (Figures $3 \mathrm{a}-\mathrm{c}$ ).

TG mice presented more extended fibrosis than WT $(25.5 \pm 15.7 \%$ vs $8.3 \pm 5.6 \%, P=0.01)$ (Figures $4 \mathrm{a}-\mathrm{d}$ ).

The quantification of the $\mathrm{OH}$-Pro content showed a higher value in BLM-treated mice than the control group
( $7.5 \pm 1.1 \%$ and $9.0 \pm 2.2 \%$ vs $6.0 \pm 2.3 \%, P=0.03$ in both cases). TG mice showed a higher OH-Pro content than WT mice $(9.0 \pm 2.2 \%$ vs $7.5 \pm 1.1 \%)$, although it was not statistically significant.

The two-way analysis of variance results, as performed by the GLM procedure, showed that interaction between SERPIN B3 expression and treatment was significant for fibrosis $(P=0.003)$, indicating that the presence of SERPIN B3 significantly increased the BLM effect on fibrosis. Real-time 
Table 1 Morphological alterations in group T20d

\begin{tabular}{|c|c|c|c|c|c|c|}
\hline \multirow[b]{2}{*}{ Parameters } & \multicolumn{2}{|c|}{ Control_-PBS (20 mice) } & \multirow[b]{2}{*}{$P$} & \multicolumn{2}{|c|}{ Treatment-BLM (20 mice) } & \multirow[b]{2}{*}{$P$} \\
\hline & $\begin{array}{c}\text { WT } \\
\text { Mean } \pm \text { s.d. }\end{array}$ & $\begin{array}{c}\text { TG } \\
\text { Mean } \pm \text { s.d. }\end{array}$ & & $\begin{array}{c}\text { WT } \\
\text { Mean } \pm \text { s.d. }\end{array}$ & $\begin{array}{c}\text { TG } \\
\text { Mean } \pm \text { s.d. }\end{array}$ & \\
\hline Architectural remodeling (\%) & $2.2 \pm 2.3$ & $1.0 \pm 0.8$ & 0.21 & $23.1 \pm 15.3$ & $16.8 \pm 9.7$ & 0.26 \\
\hline Fibrosis extension (\%) & 0.0 & 0.0 & - & $8.3 \pm 5.6$ & $25.5 \pm 15.7$ & $0.01,0.003^{a}$ \\
\hline Apoptotic index (\%) & $0.3 \pm 0.7$ & $0.4 \pm 0.7$ & 0.54 & $1.5 \pm 0.9$ & $0.9 \pm 0.8$ & 0.18 \\
\hline \multirow[t]{2}{*}{ Proliferative index (\%) } & $0.7 \pm 0.7$ & $2.6 \pm 2.4$ & 0.07 & $3.1 \pm 1.4$ & $6.5 \pm 2.9$ & 0.007 \\
\hline & (\%) & (\%) & $P$ & $(\%)$ & $(\%)$ & $P$ \\
\hline Bronchiolization grading $>2$ & $0 \%$ & $12 \%$ & 0.44 & $90 \%$ & $90 \%$ & - \\
\hline
\end{tabular}

Abbreviations: BLM, bleomycin; PBS, phosphate-buffered saline; TG, transgenic; WT, wild-type.

${ }^{a}$ General linear model analysis showed that interaction between SERPIN B3 expression and treatment was significant $(P=0.003)$.

${ }^{\mathrm{b}}$ General linear model analysis showed that interaction between SERPIN B3 expression and treatment was marginally significant $(P=0.05)$.
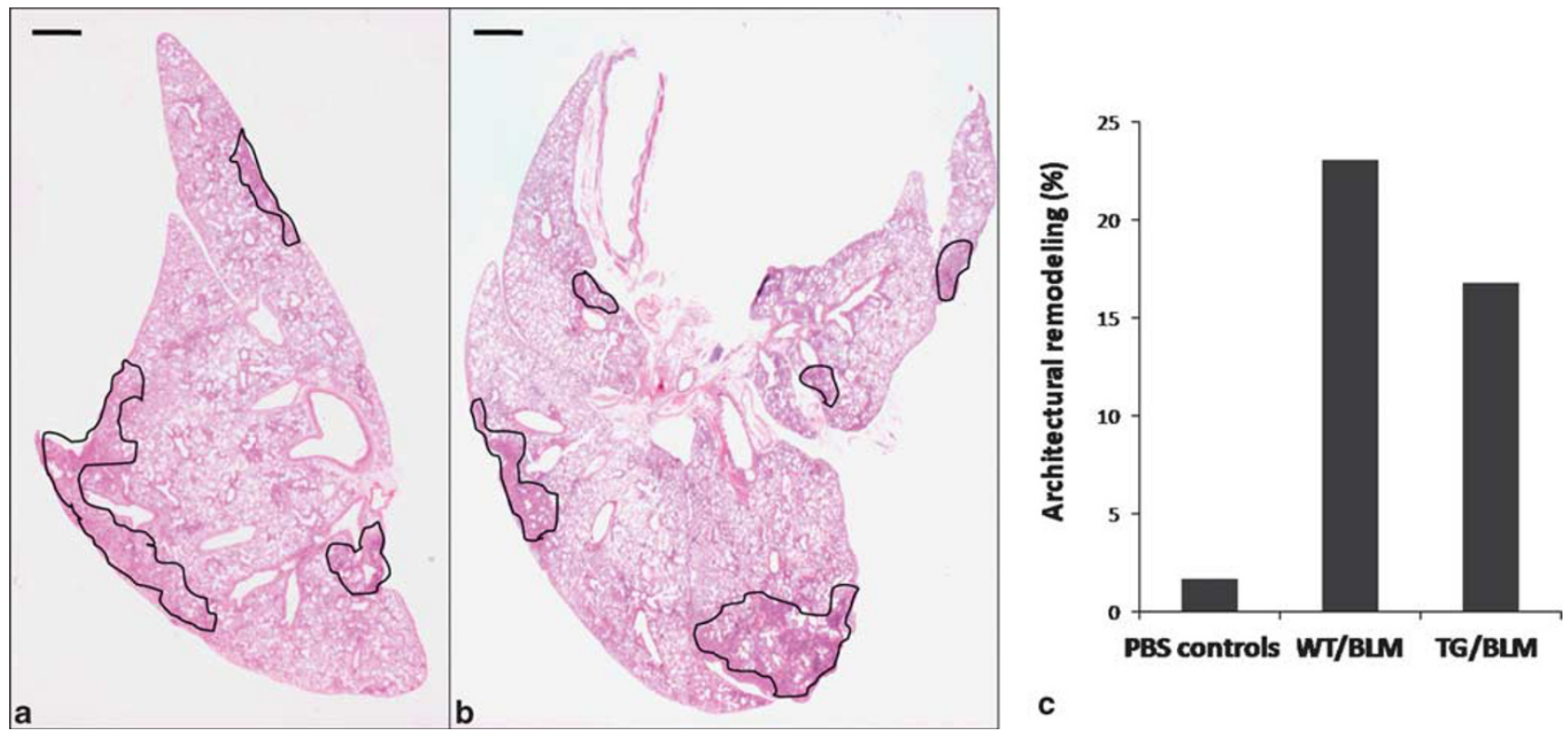

Figure 3 (a-c) Group T20d, architectural remodeling (including inflammation, fibrosis and vessel remodeling) in BLM-treated mice. H\&E stain. Condensed 'purple regions' (hematoxylinophylic areas) are morphometrically selected in WT (a) and TG (b) mice. Bar $=1 \mathrm{~mm}$. Graph shows that the remodeled area (\%) was not significantly different in the lungs of WT/BLM than TG/BLM animals (c).

PCR approach showed a higher TGF- $\beta$ expression in the TG than WT mice $(3.5 \pm 3.5$ vs $1.0 \pm 0.3, P=0.04)$ (Figure $4 \mathrm{e}$ ). Although not statistically significant, cathepsin $\mathrm{S}$ and $\mathrm{L}$ expression is lower in TG than WT mice (median $\Delta \Delta \mathrm{Ct}$ values: 3.0 and 0.4 in TG $v s 5.3$ and 1.3 in WT).

Cathepsin $\mathrm{K}$ levels were very similar in TG and WT animals (median $\Delta \Delta \mathrm{Ct}$ values: 0.8 and 0.6 , respectively). Although the AI was similar in the two groups, PI was significantly increased in TG than in WT mice $(P=0.007)$ (Figures $5 \mathrm{a}-\mathrm{d}$ ).

All WT mice showed more extensive inflammation (16.4 \pm 7.8 vs $7.2 \pm 4.6, P=0.01)$ often with numerous follicular inflammatory infiltrations localized in peribronchiolar, interstitial and subpleural areas (Figures $6 \mathrm{a}$ and $\mathrm{b}$ ). The twoway analysis of variance results, as performed by the GLM procedure, showed that interaction between SERPIN B3 

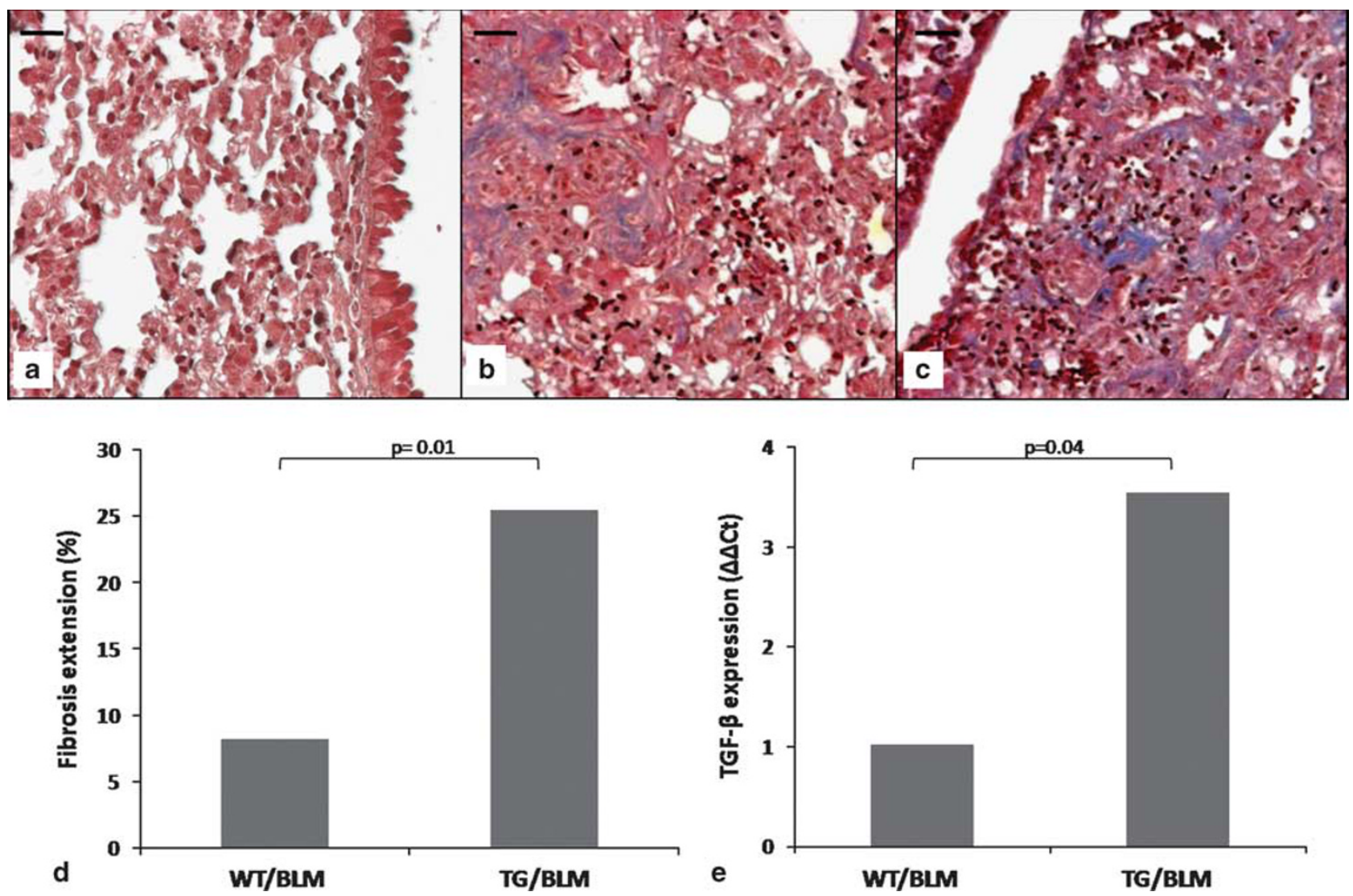

Figure 4 (a-e) Group T20d, fibrosis extension in PBS control (a), WT/BLM (b) and TG/BLM (c) mice. Azan-Mallory stain. Bar $=50 \mu \mathrm{m}$. Fibrosis was not detectable in PBS controls (a). Fibrotic extension was higher in TG/BLM (c) than in WT/BLM mice (b) Graphs show the amount of fibrotic extension (\%) in the lung parenchyma in WT/BLM and TG/BLM animals (d) $(P=0.01)$ and TGF- $\beta$ mRNA levels (e) $(P=0.04)$.

expression and treatment was significant for inflammation $(P=0.05)$, supporting that the presence of SERPIN B3 may significantly decrease the BLM effect on inflammation (Figure 6c).

Even if not statistically significant, higher rates of neoplastic transformation foci were detected in TG than WT animals (10 and $40 \%$, respectively).

\section{DISCUSSION}

This study presents in vivo evidence for a role of SERPIN B3 in inhibiting inflammation and favoring epithelial proliferation with increased TGF- $\beta$ secretion, and likely consequent fibrogenesis. Although BLM may directly cause epithelial structural damage, ${ }^{26}$ its principal mode of action in leading to IPF-like pathology seems to be via endogenous mediators of inflammation, fibrosis and proliferation. The BLMinduced lung injury in experimental models causes an extensive inflammatory background, sometimes with elective centrolobular localization. This model has been highly criticized as a representative model of human IPF. ${ }^{27}$ However, to date, it represents the most used experimental reproduction of the disease. All our mice developed extensive lung damage after BLM treatment, with a prevalent inflammatory component already evident $48 \mathrm{~h}$ after injury. Interestingly, at 20 days, SERPIN B3 TG mice showed less evident inflammation, which could be related to an anti-inflammatory influence of SERPIN B3. Many clade B SERPINs are inhibitors of cathepsin $(G, S, K, L)$, which have a well-known monocyte/granulocyte chemoattractant function. ${ }^{28-30}$ At this time, all our animals developed well evident interstitial lung fibrosis after BLM treatment, which was significantly more extensive in SERPIN B3 TG mice. This finding reinforces our previous data obtained from the study of IPF lung samples wherein more extensive fibrosis was observed in patients with higher SERPIN B3/B4 expression. ${ }^{13}$ Fibrotic remodeling could be related to the anti-inflammatory function of SERPIN B3/B4 through the downregulation of cathepsins (although this was not statistically significant in our study) or to an increased secretion of TGF- $\beta$. In lung fibrosis, there is now considerable evidence that TGF- $\beta$ has a pivotal role in the production of collagen and extracellular matrix ${ }^{31}$ as well as in promoting epithelial-to-mesenchymal transition. ${ }^{32}$ Overexpression of TGF- $\beta$ has been detected in lungs of mice after BLM induction ${ }^{33}$ and it seems to be more evident in our TG mice. The increased level of TGF- $\beta$ detected in our model could be mainly due to an enhanced number of metaplastic epithelial cells, which have been demonstrated to be an important source of this cytokine in lung fibrosis. ${ }^{13,33}$ Indeed an 

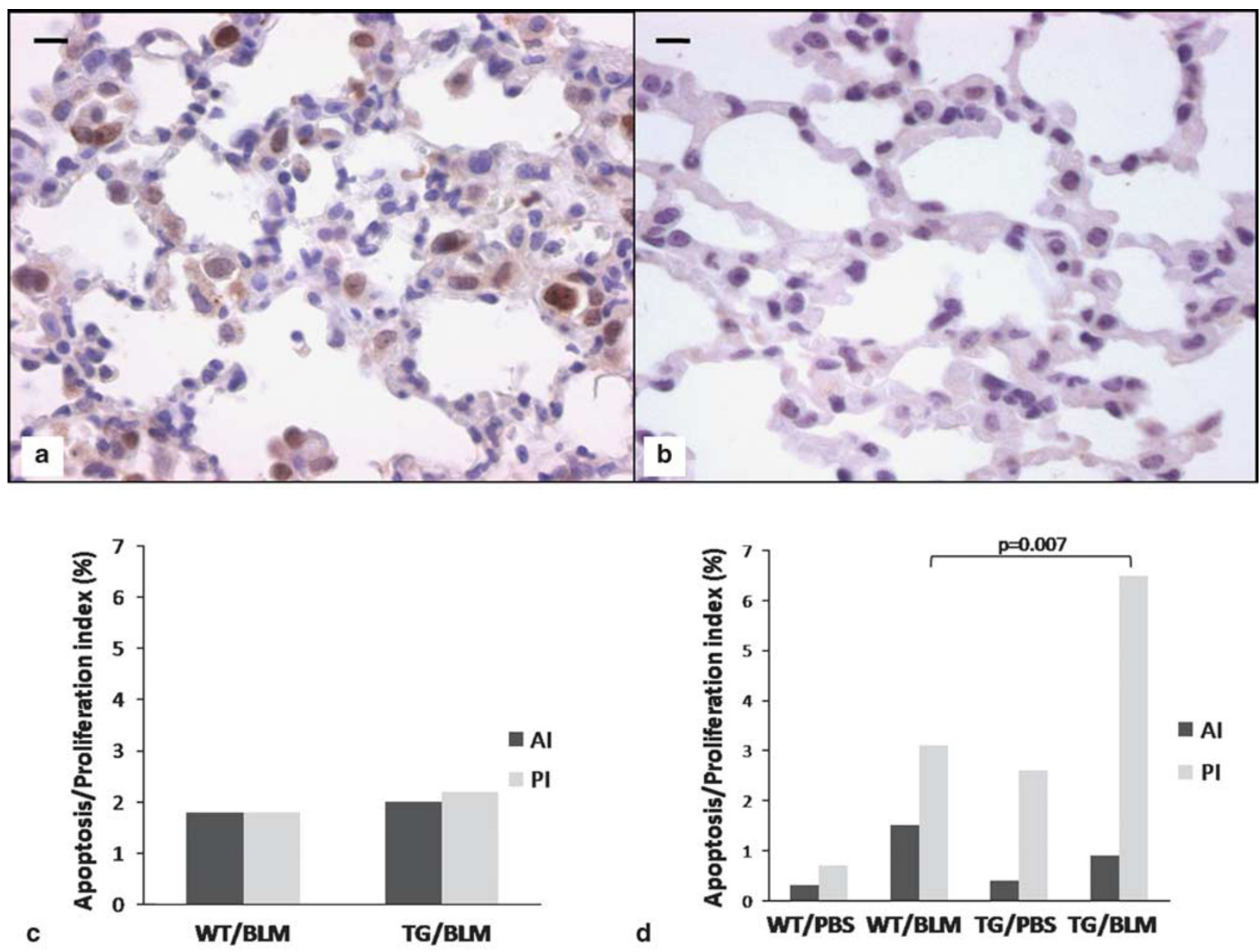

Figure 5 (a-d) Group T20d, cell proliferation: TG/BLM (a) showed more numerous proliferating epithelial cells than WT/BLM animals (b) Immunohistochemistry for Ki-67. Bar $=1 \mu \mathrm{m}$. Group T48h: graphs show similar Al and PI in WT and TG mice (c). Group T20d: a significantly higher proliferative index was found in TG after BLM administration than in WT mice $(P=0.007)(d)$.
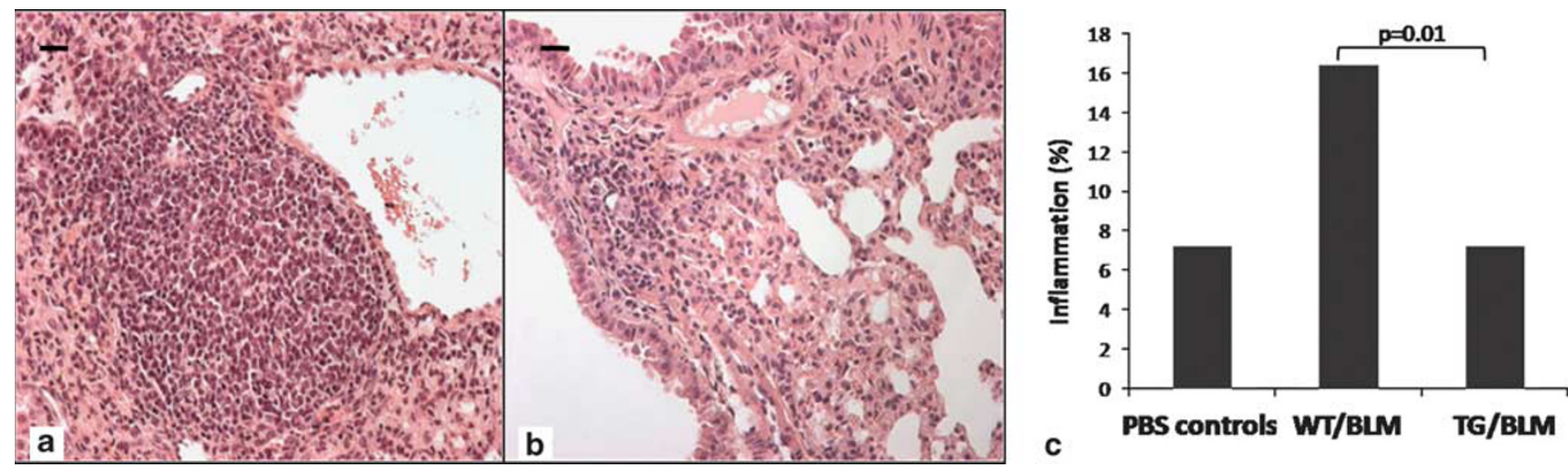

Figure 6 (a-c) Group T20d, inflammation in BLM treated mice: numerous follicular inflammatory cell infiltrates were observed in all WT mice (a). TG mice showed inflammatory cells never aggregated in a follicular pattern (b) H\&E stain. Bar $=10 \mu \mathrm{m}$. Graph shows the inflamed area (\%) in the lungs of PBS control, WT/BLM and TG/BLM animals (c). WT/BLM animals present a more extended inflamed area than TG/BLM $(P=0.01)$.

intriguing aspect of our work was the prominent epithelial proliferation in SERPIN B3 TG mice. Different serpins have demonstrated a protective role against apoptosis. Serin pro- teinases are implicated in cell death induced by TNF- $\alpha$, while their inhibitors protect tumor cells from the cytotoxic effects of TNF- $\alpha$. SERPIN B3, typically overexpressed in cancer cells 
of epithelial origin ${ }^{34}$ and of the liver, ${ }^{35}$ significantly attenuates apoptosis mediated by anti-cancer drugs or TNF- $\alpha$, allowing tumor growth. ${ }^{36}$ The molecular target location of SERPIN B3 in the apoptotic pathway has been suggested to be upstream from the caspase 3, as demonstrated in SCC Ag1 and DNA transduced PCI-51 cells after TNF- $\alpha$ induction and in 293T cells genetically engineered for SERPIN B3 after radiation therapy. ${ }^{37}$ Furthermore, SERPIN B3 has recently been indicated in the inhibition of UV-induced apoptosis through the suppression of c-jun $\mathrm{N}$-terminal kinase. ${ }^{38}$ At $48 \mathrm{~h}$ after BLM treatment (group T48 h), apoptotic cell death was equally balanced in WT and TG mice. At killing (group T20d), apoptosis persisted at the same level with a significant gain of epithelial proliferation in TG animals. In summary, this study provides in vivo evidence for a role of SERPIN B3 in reducing inflammation, influencing epithelial proliferation/apoptosis imbalance and likely favoring fibrogenesis. This experimental scenario looks like an advanced form of human IPF in which fibrotic remodeling is associated with uncontrolled epithelial proliferation and lung cancer.

Thereby overexpression or aberrant expression of SERPIN B3 may have an important role in pulmonary epithelial dysfunction of pulmonary fibrosis and could represent an interesting target for the development of new therapeutic strategies.

\section{ACKNOWLEDGEMENTS}

We thank Luca Braghetto and Laura Vignato for their excellent technical assistance and Judith Wilson for English revision. This study was supported by Italian Ministry of Instruction, University and Research.

\section{DISCLOSURE/CONFLICT OF INTEREST}

The authors declare no conflict of interest.

1. Keogh BA, Crystal RG. Alveolitis: the key to the interstitial lung disorders. Thorax 1982;37:1-10.

2. Selman M, Pardo A. Role of epithelial cells in idiopathic pulmonary fibrosis: from innocent targets to serial killers. Proc Am Thorac Soc 2006;3:364-372. Review.

3. Uhal BD. Epithelial apoptosis in the initiation of lung fibrosis. Eur Respir J Suppl 2003;44:7s-9s. Review.

4. Li X, Rayford H, Uhal BD. Essential roles for angiotensin receptor AT1a in bleomycin-induced apoptosis and lung fibrosis in mice. Am J Pathol 2003;163:2523-2530.

5. Selman M, King TE, Pardo A, American Thoracic Society; European Respiratory Society; American College of Chest Physicians. Idiopathic pulmonary fibrosis: prevailing and evolving hypotheses about its pathogenesis and implications for therapy. Ann Intern Med 2001:134:136-151.

6. Meyer EC, Liebow AA. Relationship of interstitial pneumonia honeycombing and atypical epithelial proliferation to cancer of the lung. Cancer 1965;18:322-351.

7. Hubbard $\mathrm{R}$, Venn $\mathrm{A}$, Lewis $\mathrm{S}$, et al. Lung cancer and cryptogenic fibrosing alveolitis. A population-based cohort study. Am J Respir Crit Care Med 2000;161:5-8.

8. Park J, Kim DS, Shim TS, et al. Lung cancer in patients with idiopathic pulmonary fibrosis. Eur Respir J 2001;17:1216-1219.

9. Aubry MC, Myers JL, Douglas WW, et al. Primary pulmonary carcinoma in patients with idiopathic pulmonary fibrosis. Mayo Clin Proc 2002;77:763-770.

10. Portnoy J, Mason RJ. Role of alveolar type II epithelial cells in pulmonary fibrosis. In: Lynch III JP (ed). Idiopathic Pulmonary Fibrosis. Marcel Dekker: New York, 2004.
11. Betsuyaku T, Fukuda Y, Parks WC, et al. Gelatinase B is required for alveolar bronchiolisation after intratracheal bleomycin. Am J Pathol 2000;157:525-535.

12. Odajima $N$, Betsuyaku $T$, Nasuhara $Y$, et al. Extracellular matrix metalloproteinase inducer in interstitial pneumonias. Hum Pathol 2006;37:1058-1065.

13. Calabrese F, Lunardi F, Giacometti C, et al. Overexpression of squamous cell carcinoma antigen in idiopathic pulmonary fibrosis: clinicopathological correlations. Thorax 2008;63:795-802.

14. Silverman GA, Bird PI, Carrell RW, et al. The serpins are an expanding superfamily of structurally similar but functionally diverse proteins. Evolution, mechanism of inhibition, novel functions, and a revised nomenclature. J Biol Chem 2001;276:33293-33296.

15. Mangan MS, Kaiserman D, Bird PI. The role of serpins in vertebrate immunity. Tissue Antigens 2008;72:1-10.

16. Schick C, Pemberton PA, Shi GP, et al. Cross-class inhibition of the cysteine proteinases cathepsins $\mathrm{K}, \mathrm{L}$, and $\mathrm{S}$ by the serpin squamous cell carcinoma antigen 1: a kinetic analysis. Biochemistry 1998;37: 5258-5266.

17. Suminami $Y$, Nagashima S, Vujanovic NL, et al. Inhibition of apoptosis in human tumour cells by the tumour-associated serpin, SCC antigen1. Br J Cancer 2000;82:981-989.

18. Fridlender ZG, Cohen PY, Golan $\mathrm{O}$, et al. Telomerase activity in bleomycin-induced epithelial cell apoptosis and lung fibrosis. Eur Respir J 2007;30:205-213.

19. De Falco $S$, Ruvoletto MG, Verdoliva $A$, et al. Cloning and expression of a novel hepatitis B virus-binding protein from HepG2 cells. J Biol Chem 2001:39:36613-36623.

20. Aoshiba K, Yasui S, Tamaoki J, et al. The Fas/Fas-ligand system is not required for bleomycin-induced pulmonary fibrosis in mice. Am J Respir Crit Care Med 2000;162:695-700.

21. Fridlender ZG, Cohen PY, Golan $\mathrm{O}$, et al. Telomerase activity in bleomycin-induced epithelial cell apoptosis and lung fibrosis. Eur Respir J 2007;30:205-213.

22. Izbicki G, Segel MJ, Christensen TG, et al. Time course of bleomycininduced lung fibrosis. Int J Exp Pathol 2002;83:111-119.

23. Donà $M$, Dell'Aica $I$, Pezzato $E$, et al. Hyperforin inhibits cancer invasion and metastasis. Cancer Res 2004;64:6225-6232.

24. Dell'Aica I, Sartor L, Galletti P, et al. Inhibition of leukocyte elastase, polymorphonuclear chemoinvasion, and inflammation-triggered pulmonary fibrosis by a 4 -alkyliden- $\beta$-lactam with a Galloyl moiety. J Pharmacol Exp Ther 2006;316:539-546.

25. Gavrieli $Y$, Sherman Y, Ben-Sasson SA. Identification of programmed cell death in situ via specific labelling of nuclear DNA fragmentation. J Cell Biol 1992;119:493-501.

26. Sato $E$, Koyama $S$, Masubuchi $T$, et al. Bleomycin stimulates lung epithelial cells to release neutrophil and monocyte chemotactic activities. Am J Physiol 1999;276:L941-L950.

27. Borzone G, Moreno R, Urrea R, et al. Bleomycin-induced chronic lung damage does not resemble human idiopathic pulmonary fibrosis. Am J Respir Crit Care Med 2001;163:1648-1653.

28. Schick C, Pemberton PA, Shi GP, et al. Cross-class inhibition of the cysteine proteinases cathepsins $\mathrm{K}, \mathrm{L}$, and $\mathrm{S}$ by the serpin squamous cell carcinoma antigen 1: a kinetic analysis. Biochemistry 1998;37:5258-5266.

29. Bühling F, Röcken C, Brasch F, et al. Pivotal role of cathepsin $\mathrm{K}$ in lung fibrosis. Am J Pathol 2004;164:2203-2216.

30. Srivastava M, Steinwede K, Kiviranta $R$, et al. Overexpression of cathepsin $\mathrm{K}$ in mice decreases collagen deposition and lung resistance in response to bleomycin-induced pulmonary fibrosis. Respir Res 2008;9:54.

31. Gharaee-Kermani $\mathrm{M}, \mathrm{Hu} B, \mathrm{Phan} \mathrm{SH}$, et al. Recent advances in molecular targets and treatment of idiopathic pulmonary fibrosis: focus on TGFbeta signaling and the myofibroblast. Curr Med Chem 2009;16:1400-1417. Review.

32. Kim KK, Kugler MC, Wolters PJ, et al. Alveolar epithelial cell mesenchymal transition develops in vivo during pulmonary fibrosis and is regulated by the extracellular matrix. Proc Natl Acad Sci USA 2006;103:13180-13185.

33. Zhang K, Flanders KC, Phan SH. Cellular localization of transforming growth factor-beta expression in bleomycin-induced pulmonary fibrosis. Am J Pathol 1995;147:352-361. 
34. Kato $\mathrm{H}$. Expression and function of squamous cell carcinoma antigen. Anticancer Res 1996;16:2149-2153. Review.

35. Pontisso $\mathrm{P}$, Calabrese $\mathrm{F}$, Benvegnù $\mathrm{L}$, et al. Overexpression of squamous cell carcinoma antigen variants in hepatocellular carcinoma. Br J Cancer 2004;90:833-837. Erratum in: Br J Cancer 2004;91:2103.

36. Suminami Y, Nagashima S, Murakami A, et al. Suppression of a squamous cell carcinoma (SCC)-related serpin, SCC antigen, inhibits tumor growth with increased intratumor infiltration of natural killer cells. Cancer Res 2001;61:1776-1780.

37. Murakami A, Suminami $Y$, Hirakawa $H$, et al. Squamous cell carcinoma antigen suppresses radiation-induced cell death. $\mathrm{Br} J$ Cancer 2001;84:851-858.

38. Katagiri C, Nakanishi J, Kadoya K, et al. Serpin squamous cell carcinoma antigen inhibits UV-induced apoptosis via suppression of c-JUN NH2terminal kinase. J Cell Biol 2006;172:983-990. 